Acta haemat. $1965 ; 34: 370$

\title{
Varia
}

\section{Jean Julliard Prize}

The second 'Jean Julliard Prize', so named in commemoration of the 1st Secretary General of the International Society of Blood Transfusion, is intended to encourage research work on Blood Transfusion. It will be awarded during the Xlth International Congress of Blood Transfusion to be held in Sydney (Australia) from the 24th to the 29th August 1966.

Candidates, under the age of 35 years, should forward, at least 4 months before the opening of the Congress, 4 copies of their unpublished or recently published work to the Secretary General, Dr. J. P. Soulier, 6 rue Alexandre Cabanel, Paris 15e (France).

The jury for this prize, whose value is sFr. 2000.- is composed of Dr. E. Freies-leben (President); Dr. S. T. Gibson and Dr. M. Grove-Rasmussen. 